\title{
MANEJO MECÂNICO E QUÍMICO DA AVEIA PRETA E SUA INFLUÊNCIA SOBRE A TAXA DE DECOMPOSIÇÃO E O CONTROLE DE PLANTAS DANINHAS EM SEMEADURA DIRETA DE MILHO ${ }^{1}$
}

\author{
AUGUSTO G. DE ARAÚJO² ${ }^{2}$ BENEDITO N. RODRIGUES
}

\section{RESUMO}

A formação da cobertura vegetal morta sobre a superfície do solo constitui um dos principais requisitos da semeadura direta devido a seus efeitos alelopáticos e físicos, os quais proporcionam maior eficiência no controle de plantas daninhas. O objetivo do trabalho foi avaliar a influência de seis manejos da aveia preta sobre a taxa de decomposição do vegetal e a incidência de plantas daninhas, visando a formação de cobertura morta para semeadura direta de milho. Os sistemas avaliados foram: dessecação com sulfosate; dessecação seguida da rolagem; rolagem seguida da dessecação; rolagem exclusiva; trituração exclusiva e trituração seguida da dessecação. A eficiência no controle foi avaliada através da cobertura do solo por plantas daninhas aos 35 dias após a semeadura e pelo peso de plantas daninhas na colheita do milho. Houve diferenças significativas entre os manejos quanto à taxa de decomposição da aveia e o controle de plantas daninhas. Entretanto, os tratamentos com taxas diferenciadas de decomposição foram semelhantes em relação à eficiência do controle. Os tratamentos que se diferenciaram quanto ao controle de plantas daninhas foram a dessecação seguida do rolo-faca e o rolo-faca seguida da dessecação. A combinação dos manejos mecânico e químico não trouxe nenhum benefício em relação aos manejos exclusivos e os manejos mecânicos exclusivos foram iguais entre si.

Palavras chave: Cobertura morta, rolofaca, persistência da cobertura, Avena strigosa.

\section{ABSTRACT \\ Mechanical and chemical management of black oat and its influence on decomposition rate and weed control in no-till of maize}

A good soil coverture is one of the most important direct seeding requirements because, among others factors, it improves the weed control due to the allelopathical and physical effects. The objective was to evaluate the influence of six management systems of black oat on it's decomposition rate and weed control under direct seeding of maize. The management systems evaluated were herbicide (sulfosate); herbicide before knife roller; knife roller before herbicide; knife roller; rotary shredders and rotary shredders before herbicide. The weed control efficiency was evaluated through the percentage of soil coverture 35 days after seeding and by the weight of weeds at maize harvesting. The management systems had a significative effect on decomposition rate and weed control. But treatments with different decomposition rates had the same weed control efficiency. The weed control was different between the herbicide before knife roller and knife roller before herbicide. The mechanical and chemical combined treatments didn't result in benefits compared with the same but not combined

\footnotetext{
${ }^{1}$ Recebido para publicação em 21/07/98 e na forma revisada em 21/12/99.

${ }^{2}$ Pesquisador da Área de Engenharia Agrícola do Instituto Agronômico do Paraná - IAPAR - Rodovia Celso Garcia Cid km 375 - C.P. 481. CEP: 86001970, Londrina/PR.

${ }^{3}$ Pesquisador da Área de Fitotecnia do Instituto Agronômico do Paraná - IAPAR.
} 
management systems. The mechanical management systems evaluated had the same performance.
Key words: Knife roller; rotary shredders; crop persistence; conservation tillage, Avena strigosa.

\section{INTRODUÇÃO}

A semeadura direta vem expandindo-se rapidamente no Paraná devido aos seus benefícios econômicos e ambientais e, atualmente, já é adotada em cerca de 3.800 .000 hectares, representando mais da metade da área com culturas anuais no Estado.

Uma das principais características da semeadura direta é o reduzido revolvimento do solo e a formação de uma cobertura morta sobre sua superfície, a qual pode ser constituída de restos vegetais de culturas; de forrageiras destinadas ao pastoreio ou de culturas manejadas para essa finalidade, denominadas adubos verdes.

Os efeitos positivos da cobertura vegetal sobre o solo, tais como, redução da erosão, aumento do conteúdo de água no solo e melhor controle de plantas daninhas, dentre outros, são dependentes da quantidade de massa vegetal e do tempo que a mesma persiste sobre a superfície do solo (Wagner-Riddle et al., 1994).

Almeida \& Rodrigues (1985) relatam que o efeito alelopático das coberturas mortas é tão mais intenso quanto maior a quantidade de matéria seca produzida, assegurando, assim, a concentração suficiente de toxinas para a ação letal sobre as sementes ou plântulas das plantas daninhas. Da mesma forma, maior persistência da cobertura sobre o solo possibilita que as toxinas sejam gradativamente liberadas e seus efeitos alelopáticos permaneçam por um período de tempo mais longo.

Conhecer a taxa de decomposição de coberturas vegetais na semeadura direta é importante para estimativa do tempo de permanência de seus benefícios e para o planejamento de práticas conservacionistas (Bertol et al., 1998).

O tempo de persistência da cobertura vegetal sobre o solo depende da taxa de decomposição, a qual é função da espécie e cultivar das plantas (Smith \& Peckenpaugh, 1986), especialmente da sua composição química; de parâmetros climáticos (Stroo et al., 1989), principalmente àqueles relacionados à disponibilidade de água no solo e à temperatura do ar; do tipo de solo e de suas condições químicas (Bertol, 1998 e Stroo et al., 1989); da posição relativa entre o vegetal e o solo, ou seja, na superfície ou incorporado (Douglas et al., 1980, Creus et al., 1998 e Zhiguo et al., 1998); da massa inicial da cobertura vegetal (Brown \& Dickey, 1970 citado por Douglas et al., 1980) bem como da idade do vegetal na época do manejo e do tamanho de seus fragmentos (Roman \& Velloso, 1993), de tal forma que vegetais manejados ainda na fase jovem, por exemplo no florescimento, são decompostos mais rapidamente do que plantas maduras e, quanto menores os fragmentos, mais rápida é a decomposição em conseqüência da maior área de contato dos mesmos com o solo.

Para estimar a taxa de decomposição de vegetais em diferentes condições, foram desenvolvidos alguns modelos matemáticos de simulação, os quais ainda apresentam limitações relacionadas, principalmente, aos índices climáticos e coeficientes de decomposição, à variabilidade dos dados de redução de massa vegetal coletados no campo e à combinação desses fatores (Schomberg \& Steiner, 1997).

Assim, estudos experimentais para avaliação da taxa de decomposição de coberturas vegetais permitem identificar a influência de alguns do fatores citados e possibilitam uma melhor adequação dos modelos para condições similares.

A aveia preta (Avena strigosa Schieb.) é uma das espécies recomendadas para rotação de culturas em semeadura direta no Sul do Brasil (Denardin \& Kochhann, 1993), em razão do seu abundante sistema radicular e elevada produção de matéria seca da parte aérea, o que assegura 
uma adequada cobertura do solo. Sua eficiência no controle de plantas daninhas pelo efeito alelopático também já foi verificado (Almeida, 1988).

Para manejo da cobertura de aveia preta são utilizados os métodos químico, mecânico ou a combinação entre eles, de acordo com cada situação.

As máquinas utilizadas com maior freqüência no manejo são o rolo-faca, o triturador de restos de culturas, a roçadora e a grade de discos. O manejo mecânico, contudo, é eficiente apenas quando realizado no estádio correto de desenvolvimento da aveia, ou seja, na fase de grão leitoso, quando a produção de massa vegetal atinge o máximo e a rebrota é reduzida. Manejo antecipado resulta em rebrota intensa da espécie e, posterior, na formação de sementes viáveis e competição com a cultura seguinte.

A eficiência do manejo químico, entretanto, não depende do estádio da planta, o que possibilita seu emprego em várias situações. Por outro lado, sua aplicação exclusiva, mantendo a planta ereta, favorece a emergência das plantas daninhas pela redução do sombreamento do solo e aumento de sua temperatura, conforme observou Ruedell (1995), ao comparar rolo-faca e glyphosate, combinados e exclusivos, e avaliar a infestação na soja.

Visando assegurar uma melhor cobertura do solo, a eliminação de rebrotas da cobertura morta e seu acamamento adequado, tem sido muito usada a combinação entre os manejos químico e mecânico.

As máquinas citadas para o manejo mecânico da cobertura vegetal apresentam desempenho diferenciado quanto à fragmentação do material, conforme verificado por Peche et al.(1995) em estudo com a Crotalaria juncea L..

$\mathrm{O}$ rolo-faca proporciona pouca fragmentação, sendo variável entre 200 e 300 mm o tamanho dos fragmentos, dependendo do modelo do implemento. Esta reduzida fragmentação possivelmente diminui a taxa de decomposição do material, o que tem sido apontado como uma vantagem do equipamento
(Derpsch et al., 1994).

Os trituradores de restos de culturas proporcionam uma intensa fragmentação, embora seu tamanho possa ser alterado de acordo com a velocidade de operação e com o tipo de material manejado. Na velocidade normal, próxima de 5 $\mathrm{km} / \mathrm{h}$, os fragmentos de aveia podem variar entre 50 e $150 \mathrm{~mm}$ de comprimento o que deve acelerar a decomposição, além de facilitar o transporte da cobertura morta por chuvas e ventos.

Como a intensidade dos efeitos alelopáticos e físicos da cobertura morta de aveia preta, empregada em semeadura direta, é influenciada pela taxa de decomposição, então, é possível reduzir a incidência de plantas daninhas através da seleção de métodos de manejo da cobertura vegetal que assegurem maior persistência de duração sobre o solo. Esta é a hipótese que este trabalho pretendeu verificar.

O objetivo do trabalho foi avaliar os efeitos de seis métodos de manejo da aveia preta sobre a incidência de plantas daninhas, a velocidade de decomposição da cobertura morta e a ocorrência de embuchamentos no plantio direto de milho.

\section{MATERIAL E MÉTODOS}

$\mathrm{O}$ experimento foi conduzido na estação experimental do IAPAR, em Londrina, PR, localizada a $23^{\circ} 23^{\prime}$ " latitude sul, $51^{\circ} 11^{\prime}$ " longitude oeste e a 576 metros de altitude, com clima Cfa segundo a classificação climática de Köeppen.

A aveia preta foi semeada em Latossolo Roxo distrófico à densidade de $60 \mathrm{~kg}$ de sementes por hectare e $17 \mathrm{~cm}$ de espaçamento entre linhas. A semeadora da marca Jumil, modelo 2611SH , foi configurada com disco de corte, sulcador tipo haste para fertilizantes, disco duplo para sementes e rodas compactadoras. A adubação de cobertura foi feita a lanço, na quantidade de $30 \mathrm{~kg}$ de nitrogênio por hectare.

$\mathrm{Na}$ fase de grão leitoso da aveia, aos 140 dias após a semeadura, iniciou-se a aplicação dos tratamentos, os quais consistiram nos manejos químico (dessecação) e mecânico. 
O delineamento experimental utilizado foi o de blocos casualizados com seis tratamentos e quatro repetições. Cada parcela possuía área total de $162 \mathrm{~m}^{2}(5,4 \times 30 \mathrm{~m})$.

Os tratamentos foram: 1. dessecação química ; 2. dessecação química, seguida de rolagem com rolo-faca, 8 dias após; 3. rolagem, seguida de dessecação química, 11 dias após; 4. rolagem ; 5. trituração com triturador de restos de culturas; 6. trituração, seguida de dessecação química, 11 dias após. O herbicida utilizado na dessecação foi sulfosate (Zapp, $480 \mathrm{~g} / \mathrm{l}$ ) na dose de 1,5 litro por hectare (Rodrigues \& Almeida, 1995).

Foi utilizado o rolo-faca da marca Norma, modelo RF15000, de arrasto, com largura de trabalho de $1,5 \mathrm{~m}$, distância entre facas de $20 \mathrm{~cm}$ e peso total de $700 \mathrm{kgf}$. A velocidade de trabalho foi de $7,5 \mathrm{~km} / \mathrm{h}$, o que determinou uma energia cinética de impacto das facas de 3.345 Joule.

O triturador era da marca GEVA, modelo 2010, de arrasto, com largura de trabalho de 1,95 m, 28 facas com formato "L", acionado pela tomada de potência do trator com rotação nominal do eixo de $1700 \mathrm{rpm}$. A velocidade foi de 5,0 $\mathrm{km} / \mathrm{h}$.

Treze dias após o último manejo foi semeado milho, variedade Iapar 51, no espaçamento de $0,9 \mathrm{~m}$ e adubado com $300 \mathrm{~kg} / \mathrm{ha}$ da fórmula 4-30-10.

$\mathrm{O}$ peso da cobertura morta de aveia foi avaliado tomando-se uma amostra de $1 \mathrm{~m}^{2}$ por parcela, em quatro épocas $(0,14,34$ e 68 dias após o manejo), secando-as em estufa e pesandoas, posteriormente, em balança de precisão. A redução percentual do peso foi calculada dividindo-se a diferença entre os pesos inicial e final pelo peso inicial.

A porcentagem de cobertura do solo por plantas daninhas infestantes, incluindo a rebrota da aveia preta, foi determinada visualmente aos 35 dias após a semeadura e os resultados foram transformados em arc sen $\sqrt{x / 100}$ para análise de variância e, nos casos de significância do teste $\mathrm{F}$ ao nível de $5 \%$, foi aplicado o teste de Tukey, no mesmo nível, para comparação múltipla das médias.

O peso da matéria seca total de plantas daninhas foi avaliado na colheita do milho, através de duas amostras de $1 \mathrm{~m}^{2}$ por parcela, as quais foram secadas em estufa e pesadas em balança de precisão. Os resultados foram transformados em $\sqrt{x}$ para análise de variância e, onde o teste $\mathrm{F}$ foi significativo, aplicou-se o teste de Tukey.

$\mathrm{O}$ milho foi semeado com uma máquina da marca Semeato, modelo SHM, configurada com disco de corte, sulcador tipo haste para fertilizante, disco duplo para sementes e rodas compactadoras. A população inicial desejada foi de 47.000 plantas por hectare no espaçamento de $0,9 \mathrm{~m}$ entre linhas.

$\mathrm{O}$ número de sementes de milho emergidas no oitavo, décimo segundo, décimo sexto e vigésimo primeiro dias após a semeadura, foi determinado nos $10 \mathrm{~m}$ centrais da segunda e quinta linhas de cada parcela, visando estabelecer a taxa de emergência.

Avaliou-se a produtividade de milho em uma área útil de $36 \mathrm{~m}^{2}$ em cada parcela.

Foi avaliada qualitativamente a ocorrência de falhas no corte da cobertura morta pela semeadora de milho com conseqüente acúmulo de vegetal junto aos sulcadores (embuchamento) e imperfeições no contato das sementes com o solo.

A estimativa da taxa de decomposição da cobertura morta foi realizada ajustando-se os valores de peso da matéria seca de aveia preta (MS) e dias após o manejo (DAM), através do modelo de regressão exponencial linearizada (Bertol, 1998 e Wilson \& Raymer, 1992), onde ln $\mathrm{MS}=\mathrm{a}+\mathrm{b}$.DAM. Em seguida, aplicou-se o teste $\mathrm{t}$ para avaliar a homogeneidade dos coeficientes lineares (b) das equações de regressão.

\section{RESULTADOS E DISCUSSÃO}

A cobertura morta na área experimental atingiu, em média, $7500 \mathrm{~kg} \cdot \mathrm{ha}^{-1}$ de matéria seca, o que proporcionou uma lenta secagem e alta umidade do solo na semeadura de milho. Isto dificultou a operação dos discos de corte da 
semeadora e provocou a incorporação da cobertura vegetal nos sulcos de plantio, resultando no acúmulo do material junto às hastes sulcadoras (embuchamento), notadamente nos tratamentos com rolo-faca e aveia em pé (T1, T2, T3 e T4). Nos tratamentos com triturador (T5 e T6) isto não ocorreu, pois o tamanho reduzido dos fragmentos facilitou seu desprendimento dos sulcadores da semeadora.

O estabelecimento inicial das plântulas de milho foi favorecido pela distribuição normal das precipitações a partir da segunda quinzena de outubro. O total mensal de precipitação e as temperaturas médias, máximas e mínimas, nos meses de avaliação da taxa de decomposição da aveia preta, são mostrados na Figura 1.

Não foram observadas diferenças significativas entre os tratamentos (teste F) para o número de plantas de milho emergidas (Figura 2), em nenhuma das quatro datas de observação. Portanto, a semeadora proporcionou boas condições para emergência mesmo nos tratamentos onde houve embuchamento.

A redução percentual no peso da matéria seca de aveia preta, 68 dias após os manejos, encontra-se na Tabela 1. As maiores reduções foram verificadas nos tratamentos com dessecação (T1) e trituração seguida de dessecação (T6), as quais foram significativamente diferentes da dessecação seguida da rolagem (T2). Provavelmente, o corte do vegetal pelo rolo-faca, oito dias após a dessecação, prejudicou a translocação do produto na planta e reduziu sua eficiência.

Os tratamentos mecânicos exclusivos (T4 e T5) não proporcionaram uma redução no peso diferenciada dos mesmos tratamentos combinados com dessecação posterior (T3 e T6, respectivamente). As reduções de peso para o rolo-faca e triturador exclusivos (T4 e T5) foram próximas às obtidas por Gamero et al. (1997).

A dessecação seguida da rolagem (T2) resultou, também, numa redução de peso igual àquela verificada quando se aplicou o rolo-faca exclusivamente (T4).

Não houve diferença estatística significativa entre os tratamentos para a variável cobertura vegetal em cada época de avaliação (Tabela 1).

Os coeficientes lineares das equações de regressão para cada tratamento (Tabela 2) foram comparados dois a dois, quanto à sua homogeneidade (Tabela 3), visando verificar se houve diferença significativa na taxa de decomposição devido ao manejo.

A taxa de decomposição do tratamento com dessecação exclusiva (T1) foi significativamente diferente dos tratamentos com dessecação seguida da rolagem (T2), do rolo-faca exclusivo (T4) e da trituração seguida da dessecação (T6).

Os manejos com rolo-faca exclusivo (T4) e dessecação seguida da rolagem (T2) apresentaram as menores taxas de decomposição, 46 e $28 \mathrm{kgf} \mathrm{ha}^{-1} \cdot \mathrm{dia}^{-1}$, respectivamente, e se diferenciaram dos manejos que mais favoreceram a decomposição, ou seja, T1 e T6, cujas taxas atingiram 80 e $59 \mathrm{kgf}^{-h^{-1}}{ }^{-} \mathrm{dia}^{-1}$, respectivamente.

Quanto à manutenção da cobertura vegetal morta sobre o solo, os tratamentos T2 e T4 foram, ambos, superiores aos tratamentos $\mathrm{T} 1 \mathrm{e} \mathrm{T} 6 \mathrm{e}$, como aqueles não se diferenciaram entre si, conclui-se que o uso exclusivo do rolo-faca representa uma alternativa mais econômica ao produtor, uma vez que requer apenas uma operação agrícola. Deve-se considerar, contudo, que a eficiência do rolo-faca depende do estádio da cultura a ser manejada e da uniformidade de seu desenvolvimento.

A taxa de decomposição do triturador exclusivo (T5) não se diferenciou do rolo-faca (T4), no período de observação, o que não coincidiu com o resultado obtido por Gamero et al. (1997). A diferença nos pesos iniciais da aveia entre os dois estudos (cerca de tres vezes maior no presente trabalho) foi, provavelmente, a razão da divergência entre os resultados.

Aos 35 dias após a semeadura, a percentagem de cobertura do solo por plantas daninhas (Tabela 4) foi significativamente maior nos tratamentos com triturador (T5 e T6). 


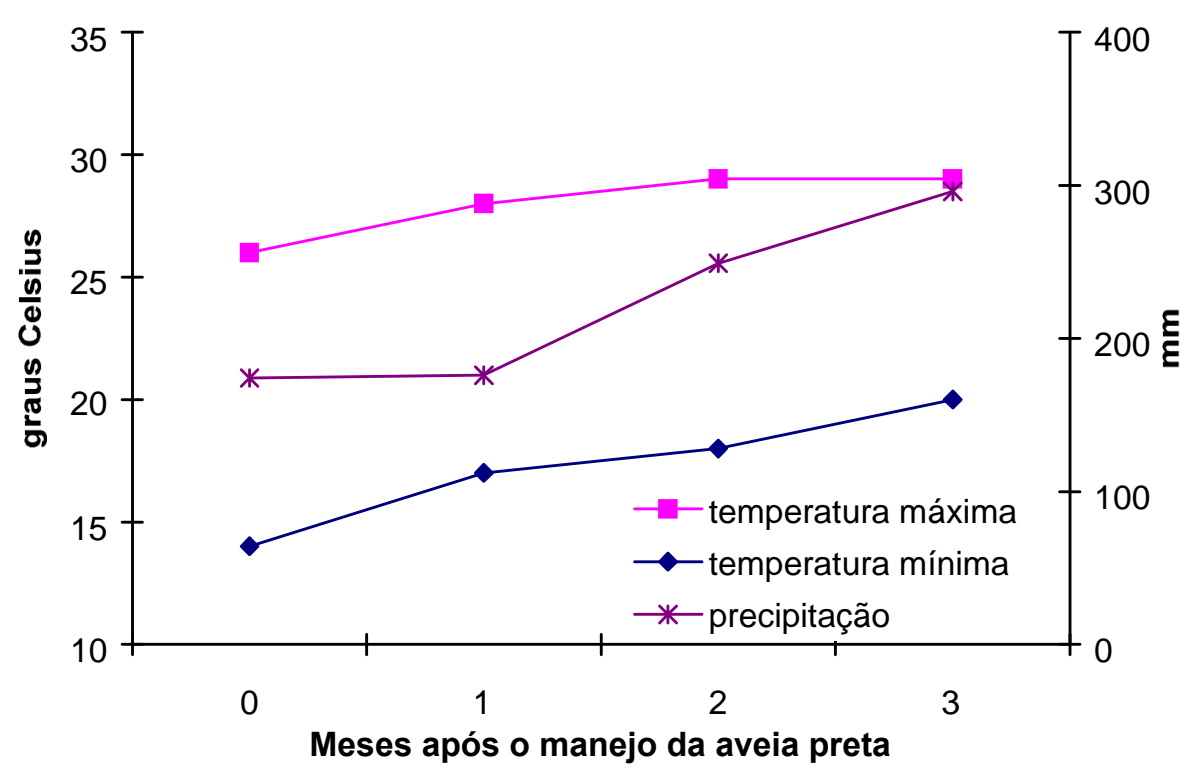

FIGURA 1. Precipitação total e temperaturas médias máximas e mínimas mensais nos meses de avaliação da decomposição a partir do manejo da aveia preta. Londrina, PR, 1996.

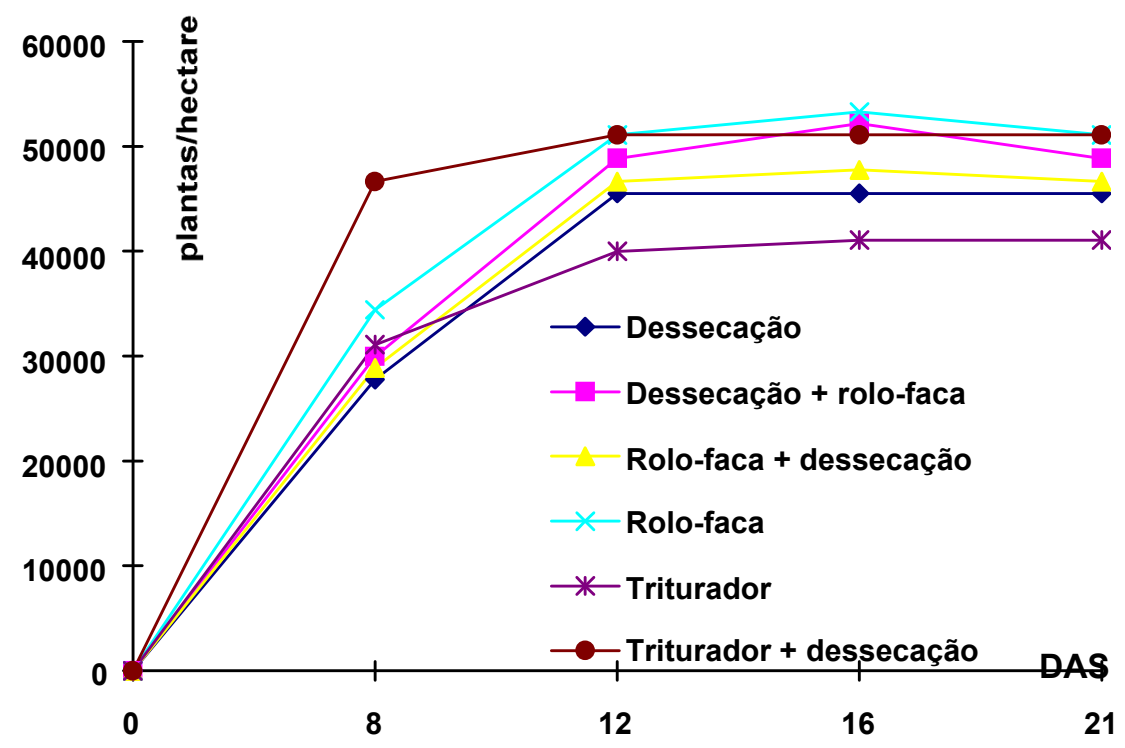

FIGURA 2. Número de plantas de milho emergidas a cada dia após a semeadura (DAS), segundo os tratamentos. Londrina, PR, 1996. 
TABELA 1. Peso observado (kgf/ha) e redução percentual no peso da matéria seca de aveia preta no período de decomposição. Londrina, PR, 1996.

\begin{tabular}{|c|c|c|c|c|c|}
\hline \multirow[t]{2}{*}{ Tratamento } & \multicolumn{4}{|c|}{ Dias após o manejo (DAM) ${ }^{1}$} & \multirow{2}{*}{$\begin{array}{c}\text { Redução do } \\
\text { peso }(\%)^{2}\end{array}$} \\
\hline & 0 & 14 & 34 & 68 & \\
\hline Dessecação (T1) & 8550 a & $7237 \mathrm{a}$ & $5162 \mathrm{a}$ & $3200 \mathrm{a}$ & $63 \mathrm{a}$ \\
\hline Dessecação/rolo-faca (T2) & 6473 a & 5830 a & 4937 a & $4525 \mathrm{a}$ & $30 \mathrm{~b}$ \\
\hline Rolo-faca/dessecação (T3) & 8225 a & $7575 \mathrm{a}$ & 4550 a & 3987 a & $51 \mathrm{ab}$ \\
\hline Rolo-faca (T4) & 7990 a & $7075 \mathrm{a}$ & 5837 a & $4812 \mathrm{a}$ & $40 \mathrm{ab}$ \\
\hline Triturador (T5) & 8112 a & 5662 a & 4087 a & $4075 \mathrm{a}$ & $50 \mathrm{ab}$ \\
\hline Trituração/dessecação (T6) & 7037 a & 5975 a & $4512 \mathrm{a}$ & 3037 a & $57 \mathrm{a}$ \\
\hline Coeficiente de variação (\%) & 12,8 & 22,4 & 25,3 & 21,6 & 15,3 \\
\hline
\end{tabular}

TABELA 2. Equações da regressão exponencial linearizada e estatística da regressão, segundo os tratamentos. Londrina, PR, 1996.

\begin{tabular}{lccc}
\hline \multicolumn{1}{c}{ Tratamento } & Equação $\cdot$ & $\left(\mathrm{R}^{2}\right) \cdots$ & Teste F $\cdots$ \\
\hline Dessecação (T1) & $\ln \mathrm{MS}=9,0661-0,0147$ DAM & 0,99 & $954,5^{* *}$ \\
Dessecação/rolo-faca (T2) & $\ln \mathrm{MS}=8,7447-0,0053$ DAM & 0,92 & $11,4^{\dagger \dagger}$ \\
Rolo-faca/dessecação (T3) & $\ln \mathrm{MS}=9,0188-0,0119 \mathrm{DAM}$ & 0,88 & $14,5^{\dagger}$ \\
Rolo-faca (T4) & $\ln \mathrm{MS}=8,9669-0,0075$ DAM & 0,98 & $119,7^{* *}$ \\
Triturador (T5) & $\ln \mathrm{MS}=8,8441-0,0095$ DAM & 0,74 & $5,6^{\dagger \dagger}$ \\
Triturador/dessecação (T6) & $\ln \mathrm{MS}=8,8581-0,0125$ DAM & 0,99 & $1362,8^{* *}$ \\
\hline
\end{tabular}

Equação exponencial linearizada; DAM = dias após o manejo e MS = peso da cobertura vegetal (kgf)

$\cdot \mathrm{R}^{2}=$ coeficiente de determinação

‥ nível de significância da regressão: ${ }^{* *}$ significativo a $1 \%$; ${ }^{\dagger}$ significativo a $10 \% ;{ }^{\dagger \dagger}$ significativo a $20 \%$. 
TABELA 3. Teste $t$ de homogeneidade dos coeficientes lineares (b) das equações de regressão, segundo os tratamentos. Londrina, PR, 1996.

\begin{tabular}{llcccc}
\hline & $\mathrm{T} 1$ & $\mathrm{~T} 2$ & $\mathrm{~T} 3$ & $\mathrm{~T} 4$ & $\mathrm{~T} 5$ \\
\hline $\mathrm{T} 2$ & $* *$ & - & $\mathrm{ns}$ & $\mathrm{ns}$ & $\mathrm{ns}$ \\
$\mathrm{T} 3$ & $\mathrm{~ns}$ & $\mathrm{~ns}$ & - & $\mathrm{ns}$ & $\mathrm{ns}$ \\
$\mathrm{T} 4$ & $* *$ & $\mathrm{~ns}$ & $\mathrm{~ns}$ & - & $\mathrm{ns}$ \\
$\mathrm{T} 5$ & $\mathrm{~ns}$ & $\mathrm{~ns}$ & $\mathrm{~ns}$ & $\mathrm{~ns}$ & - \\
$\mathrm{T} 6$ & $*$ & $*$ & $\mathrm{~ns}$ & $* *$ & $\mathrm{~ns}$ \\
\hline
\end{tabular}

** significativo a $1 \%$ de probabilidade ; $*$ significativo a $5 \%$ de probabilidade ; ns = não significativo

TABELA 4. Percentagem de cobertura do solo por plantas daninhas e total (plantas daninhas + rebrota de aveia) aos 35 dias após a semeadura e peso de plantas daninhas na colheita do milho, segundo os tratamentos. Londrina, PR, 1996.

\begin{tabular}{lccc}
\hline \multicolumn{1}{c}{ Tratamento } & $\begin{array}{c}\text { Plantas } \\
\text { daninhas }\end{array}$ & Total $^{\mathbf{1}}$ & $\begin{array}{c}\text { Peso na colheita } \\
(\mathbf{k g f} / \mathbf{h a})^{2}\end{array}$ \\
\hline Dessecação (T1) & $10,5 \mathrm{a}$ & $21,7 \mathrm{ab}$ & $878 \mathrm{a}$ \\
Dessecação/rolo-faca (T2) & $11,0 \mathrm{a}$ & $17,2 \mathrm{~b}$ & $1187 \mathrm{a}$ \\
Rolo-faca/dessecação (T3) & $11,5 \mathrm{a}$ & $32,7 \mathrm{a}$ & $1347 \mathrm{a}$ \\
Rolo-faca (T4) & $8,5 \mathrm{a}$ & $22,7 \mathrm{ab}$ & $601 \mathrm{a}$ \\
Triturador (T5) & $19,0 \mathrm{~b}$ & $25,5 \mathrm{ab}$ & $912 \mathrm{a}$ \\
Triturador/dessecação (T6) & $20,3 \mathrm{~b}$ & $24,0 \mathrm{ab}$ & $1211 \mathrm{a}$ \\
\hline Coeficiente de variação (\%) & 9,0 & 15,1 & 19,5 \\
\hline
\end{tabular}

${ }^{1}$ Em cada coluna, médias seguidas de mesma letra não diferem entre si pelo teste de Tukey ao nível de $5 \%$ de probabilidade. Dados transformados em arc sen $\sqrt{x}$ para análise estatística.

${ }^{2}$ Dados transformados em $\sqrt{x}$ para análise de variância.

Porém, ao analisar a cobertura total, ou seja, a presença de plantas daninhas juntamente com a rebrota da aveia, esses tratamentos não se diferenciaram dos demais. A intensa fragmentação da cobertura vegetal pelo triturador diminuiu a rebrota da aveia preta e reduziu o sombreamento da superfície do solo, favorecendo a germinação das plantas daninhas.

O tratamento com dessecação seguida da rolagem (T2) foi mais eficiente no controle da rebrota da aveia em relação à rolagem seguida da dessecação (T3), provavelmente porque o período de tempo entre as duas operações, em T3, não permitiu a recuperação parcial da aveia (rebrota), o que prejudicou a absorção e translocação do herbicida pela planta. 
Desse modo, dependendo das condições ambientais, a dessecação após rolagem pode retardar e prejudicar o efeito do manejo químico.

A combinação dos manejos químico e mecânico com rolo-faca (T2 e T3) não trouxe nenhuma vantagem em relação aos manejos exclusivos (T1 e T4) tanto na incidência de plantas daninhas como na rebrota da aveia (Tabela 4).

Não foram identificadas diferenças significativas entre os tratamentos na variável peso de infestantes na colheita do milho (Tabela 4). Nesse caso, os efeitos das coberturas mortas sobre a infestação foram reduzindo-se com o tempo e os tratamentos tenderam a se igualar. As diferenças observadas entre os tratamentos quanto à taxa de decomposição da cobertura morta e ao controle de plantas daninhas, não determinaram diferenças significativas na produtividade do milho, como mostram os resultados na Tabela 5.

TABELA 5. Produtividade do milho segundo os tratamentos. Londrina, PR, 1996.

\begin{tabular}{lcc}
\hline \multicolumn{1}{c}{ Tratamento } & kgf/ha & \% \\
\hline Dessecação (T1) & 5015 a & 82 \\
Dessecação/rolo-faca (T2) & 5918 a & 97 \\
Rolo-faca/dessecação (T3) & 5275 a & 87 \\
Rolo-faca (T4) & 5072 a & 83 \\
Triturador (T5) & 4878 a & 80 \\
Triturador/dessecação (T6) & 6081 a & 100 \\
\hline Coeficiente de variação (\%) & 12,4 & - \\
\hline cada coluna, médias seguidas de mesma letra não diferem entre si pelo teste de Tukey ao nível de 5\% de probabilidade.
\end{tabular}

\section{LITERATURA CITADA}

ALMEIDA, F.S. A alelopatia e as plantas. Londrina, IAPAR, $1988.60 \mathrm{p}$. (IAPAR, Circular 53).

ALMEIDA, F.S. \&. RODRIGUES, B.N. Guia de herbicidas. Contribuição para o uso adequado em plantio direto e convencional. Londrina, IAPAR, 1985. 468 p.

BERTOL, I.; CIPRANDI, O.; KURTZ, C.; BAPTISTA, A.S. Persistência dos resíduos culturais de aveia e milho sobre a superfície do solo em semeadura direta. Rev. Bras. Ciênc. Solo, 22:705-712, 1998.

CREUS, C.J.; STUDDERT, G.A.; ECHEVERRIA, H.E.; SANCHEZ,S.R. Descomposicion de residuos de cosecha de maiz y dinamica de nitrogeno en el suelo. Cienc. Suelo, 16:2, 51-57, 1998.

DENARDIN, J.E.\&. KOCHHANN, R.A. Requisitos para a implantação e a manutenção do sistema plantio direto. In: Plantio direto no Brasil. Passo Fundo, Aldeia Norte, 1993. p.19-27. 
DERPSCH, R; ROTH, C.H.; SIDIRAS, N.; KÖPEK, U. Controle de erosão no Paraná, Brasil: sistemas de cobertura do solo, plantio direto e preparo conservacionista do solo. Eschborn, GTZ, 1991. 222p.

DOUGLAS Jr., C.L.; ALLMARAS, R.R.; RASMUSSEN, P.E.; RAMIG, R.E.; ROAGER Jr., N.C. Wheat straw composition and placement effects on decomposition in dryland agriculture of the Pacific northwest. Soil Sci. Soc. Am. J., 44:833-837, 1980.

GAMERO, C.A., SIQUEIRA, R., LEVIEN, R., SILVA., S.L. Decomposição da aveia preta (Avena strigosa Schieb.) manejada com rolo faca e triturador de palhas. In: CONGRESSO BRASILEIRO DE ENGENHARIA AGRÍCOLA, 26, 1997, Campina Grande-PB. Anais...Campina Grande, Sociedade Brasileira de Engenharia Agrícola / UFPB, 1997. (Arquivo Mag 027, editado em cd-rom).

PECHE FILHO, A.; STORINO, M.; LINO, A.C.L. Roteiro metodológico para avaliação da fragmentação realizada por picadoras, rolos-facas, roçadoras e grades de discos. In: CONGRESSO BRASILEIRO DE ENGENHARIA AGRÍCOLA, XXIV. Viçosa, MG, 1995. Resumos. Viçosa, Sociedade Brasileira de Engenharia Agrícola, 1995. p. 347.

RODRIGUES, B.N. \& ALMEIDA, F.S. Guia de herbicidas. $\quad 3^{\mathrm{a}}$ edição, Londrina, Edição dos autores, 1995. $675 \mathrm{p}$.

ROMAN, E.S.\& VELLOSO, J.A.R.O. Controle cultural, coberturas mortas e alelopatia em sistemas conservacionistas. Plantio direto no Brasil. Passo Fundo, Aldeia Norte, 1993. p.77-84.

RUEDELL, J. Plantio direto na região de Cruz Alta. Convênio FUNDACEP/BASF. FUNDACEP FECOTRIGO, Cruz Alta, RS, 1995.

SCHOMBERG, H.H. \& STEINER, J.L. Comparison of residue decomposition models used in erosion prediction. Agron. J., 89:911-918, 1997.

SMITH, J.H. \& PECKENPAUGH, R.E. Straw decomposition in irrigated soil: comparison of twenty-three cereal straws. Soil Sci. Soc. Am. J., 50: 928-932, 1986.

STROO, H.F.; BRISTOW, K.L.; ELLIOT, L.F.; PAPENDICK, R.I.; CAMPBELL, G.S. Predicting rates of wheat residue decomposition. Soil Sci. Soc. Am. J., 53:91-99, 1989.

WAGNER-RIDDLE， C.; GILLESPIE， T.J.; SWANTON, C.J. Rye cover crop management impact on soil water content, soil temperature and soybean growth. Can. J. Plant Sci., 74:485-495, 1994.

WILSON, D.O. \& RAYMER, P.L. Decomposition of sorghum residue in a double crop sorghum and wheat system. Soil Biol-Biochem., 24: 789-93, 1992.

ZHIGUO, Z.; QI, X.; BLEVINS, R.L. Effects of tillage management systems on residue cover and decomposition. Pedosphere, 8:193-200, 1998. 